\title{
HOW TO CREATE TELEMEDICINE EASILY IN PSYCHIATRY PRACTICE IN COMMUNITY
}

\author{
Nur Alia Syazwani Binti Mohd Anuar ${ }^{1}$, Zuhrotun Ulya $^{2}$ \\ Correspondence: aliosyazwani@gmail.com \\ ${ }^{1}$ Housemanship Program in Kuala Lumpur (Malaysia), ${ }^{2}$ Psychiatry Department Rumah Sakit Universitas Brawijaya (Indonesia)
}

\section{ABSTRACT}

Telemedicine is an emerging industry with the ability to revolutionize healthcare delivery for the benefit of consumers, providers and payors. In general, it is a common concept which is used to define various aspects of healthcare at a distance. Telemedicine has been revealed as one potential solutions to some of the medical dilemmas that are faced by many developing countries. In recent years, the burden of caregiving for mental illness service users has been alarming due to the lack of resources in mental health services. The problem of treatment for mental illness in Malaysia and Indonesia is now becoming more complicated with people who have different attitudes and views. In this paper, we will discuss the current state and embracement of telemedicine in psychiatry (telepsychiatry) in developing countries in South-East Asia (SEA) in general, with Malaysia and Indonesia in particular.

Keywords: telemedicine, telepsychiatry, psychiatry, Malaysia, Indonesia.

\section{Article History:}

Received: March 22, 2020

Accepted: June 18, 2020

Published: September 28, 2020
Cite this as: Syazwani, N. A., \& Ulya, Z. How to create telemedicine easily in psychiatry practice in community. Journal of Psychiatry Psychology and Behavioral Research; 2020. 2: 1-3.

\section{INTRODUCTION}

Telecommunication technologies are used within the field of health care in many different ways and have the ability to revolutionize patient care. These technologies will allow remote patients to access healthcare, as well as to promote the exchange of knowledge between healthcare workers. ${ }^{1}$

Telemedicine broadly refers to the use of information and telecommunication technologies to distribute information or expertise necessary for providing or delivering healthcare services among geographically separated participants, including physicians and patients. ${ }^{2}$ By eliminating distance as a medical care factor, telemedicine can be seen as effective in addressing some of the access, efficiency, and cost challenges faced by public and private healthcare providers. ${ }^{3}$

Telepsychiatry is one of the telemedicine technologies used to provide medical care over distance and it dates back to the early 1950's. ${ }^{4}$ Although most of the projects have evolved over the last 10 years, primarily due to advances in information. ${ }^{5}$

Telepsychiatry has been used in a variety of settings, with a variety of populations, and for a wide range of problems. However, overall, its use has remained low. ${ }^{6}$ The reluctance of patients to use telemedicine as an effective means of providing healthcare services also been mentioned as one of the main reasons for this low usage. ${ }^{7}$

\section{METHOD}

This paper tries to re review about community's difficulties (ASEAN countries but we would concentrate on Malaysia and Indonesia) in embracing telemedicine especially in telepsychiatry and steps that can be taken to resolve it based on literature review.

\section{DISCUSSION}

Telemedicine involves the use of modern information technology, especially two-way interactive audio or video communication and computers to deliver health service to remote patients and to facilitate information exchange between primary care physician and specialist at some distance from each other. ${ }^{7}$

Telepsychiatry has been described as the delivery of healthcare and the exchange of healthcare information for the purposes of providing psychiatric services across distance. $^{5}$

\section{EPIDEMIOLOGY}

Malaysia sits at the heart of South East Asia with a population of 23 million people of diverse ethnicity, cultures and religious backgrounds. It was estimated in 2000 that approximately $10.7 \%$ of the population was diagnosed with mental illness. 
These numbers are quite high and are based only on estimates from hospitals. ${ }^{8}$

Therefore, the actual number of people living with mental illness nationwide remains unknown. Nonetheless, findings from other studies conducted in Malaysia's urban and rural areas have put the prevalence of mental illness in the population between $9.6 \%$ and $35 \%$ respectively. ${ }^{9}$

In Malaysia, among all government and private hospitals only those newly set up have adopted telemedicine practice and the degree among implementation is still very much at an infant level. As for the rest of the existing old hospitals, the biggest hurdle seems to be inadequate budget. ${ }^{10}$

Other reasons include inadequate existing facilities and expertise, and the reluctance of the administrator to phase in the systems to replace the existing obsolete one. All this has significantly hindered the country's extensive in telemedicine. Besides Malaysia, the fact is that many developing countries still lack the understanding and education in the importance of telemedicine. ${ }^{10}$

Indonesia, the neighbouring nation of Malaysia is archipelago, a nation consisting of thousands of islands with an approximate population of about 220 million. The lack of medical experts is spread unevenly and concentrated mostly in major cities such as Jakarta, Bandung, Surabaya and Denpasar. ${ }^{11}$

The country's geographical existence, which consists of many islands is the key restriction in raising consciousness among people about social healthcare. Telemedicine is therefore potentially the most effective way to address health problems in the world, in addition to educating citizens on health issues. $^{11}$

The province of Aceh, Indonesia has suffered enormously from the devastating Tsunami in 2004. Culture and stigma have great responsibility for the heavy burden of mental illness in Aceh. Aceh can be viewed as a model of mental health system development after the Tsunami disaster. ${ }^{12}$

One year after exposure to the Tsunami, $24.6 \%$ of children aged between $4-10$ years and $35.6 \%$ of those aged between 11 18 years were also found to suffer from post-traumatic stress disorder (PTSD). ${ }^{13}$ Approximately $69.8 \%$ and $60.3 \%$ respectively of Tsunami survivors who had been displaced and stayed in camps reported substantial emotional distress and depression. ${ }^{14}$

The study also highlighted that a major indicator of overall suffering was the number of family members who died in the Tsunami. Additionally, children and adolescents living in relocation camps were three times more likely to suffer from Tsunami-related anxiety than those living in villages. ${ }^{14}$

Four and a half years after the Tsunami, the long-term effects of mild, severe and very severe symptoms of PTSD were found in $40.7 \%, 21.4 \%$ and $1 \%$ of adolescents respectively. ${ }^{14}$

\section{MENTAL HEALTH BELIEFS}

Malaysia comprises three main ethnic groups: the Malays (66.1\%), Chinese (25.3\%) and Indians (7.4\%). The Malays are the indigenous people of Malaysia and follow the teachings of Islam. The majority of the Chinese claim affiliation with Christianity and Buddhism, while a sizeable number of Indians are Hindus. Consequently, Malaysia's conceptions of mental illness and mental health can and have been discussed from various viewpoints, reflecting the presence of different races and religious views. ${ }^{15}$

The cultural assumption has brought a different definition of "mental health" which could have a different viewpoint on what mental health actually is. The concept of mental health amongst Malays can be summarised as heredity, periodicity, congenital, brain strain, stress (including interpersonal), susceptibility, infection, contagion, delayed onset, conditioning, and resistance. ${ }^{16}$

The concept of mental health amongst Indians focuses on the idea of dichotomy between the mind and the body. The Chinese concepts of mental health are influenced by the traditional Chinese medical beliefs based on Confucianism and Taoism. ${ }^{17}$

The vast majority of the Indonesia populations are Muslim, and their religious faith also affects their understanding of mental illness. Mental disorder is also seen in this culture as a measure of God. The belief is also widespread in other countries among Muslim society. Every condition that someone experiences, including mental illness is seen as a measure to strengthen the faith to God. ${ }^{18}$

\section{TELEMEDICINE DEVELOPMENT}

Telemedicine began in 1900's in Malaysia. This country di divided into peninsular (mainland) and Eastern Malaysia, which is an island with two states - Sarawak and Sabah along with Indonesian owned Kalimantan. Since both states are isolated from their peninsular counterparts, it is unavoidable that the states are among the less-developed states in this country. The need for telemedicine applications is even more crucial. In 2001, Malaysia's health ministry embarked telemedicine for the country as a whole. ${ }^{10}$

Indonesia's first computer and satellite based telemedicine project started in 1985-1987. ${ }^{19}$ A low-cost "Still Picture Transmission by Narrowband Technique" for educational and medical facilities was then performed in the early 1990's followed by a series of image processing experiments in a laboratory scale, which required further field tests regarding operational application. ${ }^{20}$

A satellite-telemedicine experiment was conducted later in 1997 between three institutions - Faculty of Medicine and Faculty of Engineering of the UNJANI in Bandung as the control station, while the Central Hospital of Mataram (Lombok, about $500 \mathrm{~km}$ east of Bali) and the Harapan Kita Hospital in Jakarta as the clients. ${ }^{21}$

\section{CHALLENGES IN PRACTISING TELEMEDICINE AND TELEPSYCHIATRY IN MALAYSIA AND INDONESIA}

A variety of factors have caused to the downfall of telemedicine and telepsychiatry programmes. Many programmes fail because of inadequate needs assessment, inadequate financial and other administrative support from the leadership, or the fact that telemedicine and telepsychiatry is not a match for the overall mission of the organisation. ${ }^{22}$ In terms of clinical issues, inadequate support from the specialists (psychiatrist) providing the consultations, the absence of a physician champion, and beginning with cases that are too complex may hinder development. Inadequate technical support - in initiation, maintenance and troubleshooting emergencies - alienates patients and clinicians alike. $^{23}$

The development of telemedicine in Malaysia and Indonesia has been riding a rough tide, being hampered by machine failure, insufficient maintenance of equipment and lack of substitutes for teleconsultants who were on leave or transfer. The current and future issues include lack of senior staff, frequent turnover of staff, low-end equipment, poor quality 
images, slow Internet connections and insufficient funds for maintenance. ${ }^{10}$

\section{WAYS OF OVERCOMING THE CHALLENGES}

There are five primary which drive healthcare industry changes and directions: ${ }^{24}$

- Increase in government regulations

- The growth of managed care

- Mergers in the medical sector

- Mergers in the business sector

- The focus on disease management

Diagnostic accuracy is improving over time, and with better equipment, it can be improved further. With the recent launching of the broadband and Wi-Fi technology, hopefully it will further spur the development of telemedicine applications in Malaysia and Indonesia. ${ }^{25}$

\section{CONCLUSION}

Mental health in Malaysia and Indonesia, are in some ways comparable to the situation in other (developing) countries. Poverty is impeding family access to adequate health treatment. Stigma also causes the family to conceal the patient and their condition, while lack of mental health awareness makes them want to seek a non-professional care.

Telemedicine, although a laudable breakthrough in the medical field, in reality it is not enough to provide for public health in this region, at least not in the near future. Telemedicine just cannot catch up with the needy majority. Nevertheless, telemedicine is here to offer aid for mankind. And needless to say, it is a science here to stay in the mainstream of the medical field.

The future use of telepsychiatry and other technologies is uncertain. For telepsychiatry, its curve of growth or decline will depend on how well programmes are organised, adapt and deal with potential pitfalls.

\section{Conflict of interest}

No conflict of interest in this study.

\section{References}

1. Maheu M., Whitten P. \& Allen A. (2011) E-Health, Telehealth and Telemedicine. Jossey-Bass, San Francisco, CA.

2. Coiera E. (2013) Guide to Health Informatics. Arnold, London.

3. Norris A.C. (2013) Essentials of Telemedicine and Telehealth. John Wiley and Sons Ltd, Chichester.

4. American Psychiatric Association. Resource document on telepsychiatry by videoconferencing (on line). Available from URL:http:/www.psych.org (accessed March 22, 2020).

5. Wheeler $T$. In the beginning telemedicine and telepsychiatry . T elemed T oday 2009;2:2-4.

6. Hilty DM, Luo JS, Morache Ch. et al. Telepsychiatry: An overview for psychiatrists. CNS Drugs 2012;16: 527-548.

7. May C, Gask L, Atkinson T, et al. Resisting and pro- moting new technologies in clinical practice: the case of telepsychiatry. Social Sci Med 2011;52:1889-1901.

8. Jamaiyah, H. (2011). Community mental health in Malaysia: Marriage of psychiatry and public health. Buletin Kesihatan Masyarakat Isu Khas, 155-166.

9. Crabtree, S., \& Chong, G. (2000). Standing at the crossroads: Mental health in Malaysia since independence.
In A. Haque (Ed.), Mental Health in Malaysia: Issues and Concerns. Kuala Lumpur: University Malaysia Press.

10. Ramiya S, Teleradiology in Malaysia: Problems and potential, Med Tribune Mag, Vol. 5, 15-31 August, 2014.

11. Suksmono AB, Sastrokusumo U, Suryana J, Priyanto BE, Application of image coding system based on vector quantization using SOFM-NN algorithm for X-ray images, Proc IEEE ISPACS, 1999, pp. 613-616.

12. Wiguna, T., Guerrero, A.P.S., Kaligis, F., Khamelia, M., 2010. Psychiatric morbidity among children in North Aceh district (Indonesia) exposed to the 26 December 2004 tsunami. Asia-Pacific Psychiatry 2, 151-155. doi:10.1111/j.1758-5872.2010.00079.x.

13. Agustini, E.N., Asniar, I., Matsuo, H., 2011. The prevalence of long-term post-traumatic stress symptoms among adolescents after the tsunami in Aceh. J. Psychiatr. Ment. Health Nurs. 18, 543-9. doi:10.1111/j.13652850.2011.01702.x

14. Sauza, R., Bernatsky, S., Reyes, R., de Jong, K., 2017. Mental Health Status of Vulnerable Tsunami-Affected Communites: A Survey in Aceh Province, Indonesia. J. Trauma. Stress 20, 263-369. doi:10.1002/jts.

15. Resner, G., \& Hartog, J. (2014). Concept and terminology of mental disorder among Malays. Journal of Crosscultural Psychology, 1(4), 369-382. http://dx.doi.org/10.1177/135910457000100409

16. Wig, N. N. (2011). Mental health and spiritual values. A view from the East. International Review of Psychiatry, 11(2-3), 92-96. http://dx.doi.org/10.1080/09540269974230

17. Yip, K. S. (2015). Family caregiving of clients with mental illness in the People's Republic of China. International Journal of Psychosocial Rehabilitation, 10(1), 35-42.

18. Epping-Jordan, J.E., van Ommeren, M., Ashour, H.N., Maramis, A., Marini, A., Mohanraj, A., Noori, A., Rizwan, H., Saeed, K., Silove, D., Suveendran, T., Urbina, L., Ventevogel, P., Saxena, S., 2015. Beyond the crisis: building back better mental health care in 10 emergencyaffected areas using a longer-term perspective. Int. J. Ment. Health Syst. 9, 1-10. doi:10.1186/s13033-015-0007-9

19. Suksmono AB, Sastrokusumo U, A client-server architecture of a lossy-to-lossless VQ-based medical image coding system for mobile tele-diagnosis: A preliminary design and result, Proc APT Workshop, 2012, pp. 130-133.

20. Suksmono AB, Sastrokusumo U, Mengko TLR, Pramudito JT, Oktowaty S, Overview of telemedicine activities in indonesia: Progress and constraints, Enterprise Networking and Computing in Healthcare Industry Proc, 2014, pp. $37-40$.

21. Suksmono AB, Mengko TLR, Rohmah RN, Secapawati D, Pramudito JT, Sastrokusumo U, A lossy-to-lossless clientserver medical image coding system: Web- based implementation by using java RMI, Proc 2nd APT Telemedicine Workshop, 2014.

22. Nesbitt TS, Hilty DM, Kuenneth T, et al. Development of a successful telemedicine program. West J Med 2009; 173: 169-74

23. Darkins A. Program management of telemental health care services. J Geriatric Psychiatry Neurol 2011; 14: 80-7

24. Frommer MH, Telemedicine: The Next Generation Is Here, Telcordia Technologies Inc., 2009.

25. Kho YY, Saim HB, Soon CF, Remote monitoring of vital physiological signs, Student Conference on Research and Development, 2012, pp. 69-71. 